\title{
Isolation and Characterization of Multiple Drug Resistant Human Enteric Pathogens from Sewage Water of Delhi
}

\author{
Rudrangshu Chatterjee*, Dushyant Singh**, Swati Tripathi*, Abhishek Chauhan***†, M.L Aggarwal** \\ and Ajit Varma* \\ *Amity Institute of Microbial Technology, Amity University, Sector-125, Noida, India \\ **Shriram Institute for Industrial Research, 19, University Road, Delhi-110007, India \\ ***Amity Institute of Environmental Toxicology, Safety and Management, Amity University, Sector-125, Noida, India \\ $\dagger$ Corresponding author: Abhishek Chauhan; akchauhan@amity.edu
}

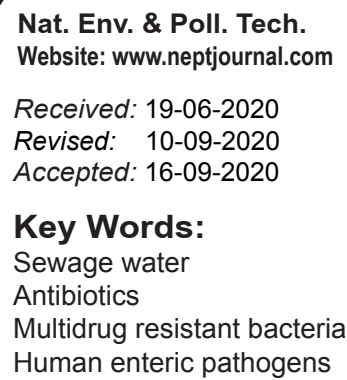

\begin{abstract}
Antibiotic resistance is one of the major problems in the medical world, and the sewage waters are the primary habitats to harbour antibiotic resistance bacteria (ARB) especially multi-drug resistance (MDR) human enteric pathogens. The present study dealt with isolation, identification and characterization of human enteric pathogens showing resistance against ten different commonly prescribed antibiotics. These bacterial strains were isolated from different sewage treatment plants located in the suburb of Delhi. Initially, samples were analysed for the presence of pathogenic human enteric bacteria through morphological, biochemical and molecular analysis. Further susceptibility patterns of these isolates were studied towards clinically significant antibiotics. Doxycycline and Metronidazole were found to be most inert antibiotic as it was ineffective against all isolated enteric pathogens, whereas Meropenem was found to be most promising antibiotic. As the resistance of these microorganisms is evolving day by day, proper steps should be taken to prevent it.
\end{abstract}

\section{INTRODUCTION}

Pollution in source water is a problem in developing as well as in all developed countries. In the past few decades, uncontrolled urbanization has caused a serious pollution problem due to the disposal of sewage and industrial effluents to water bodies. Effluent wastewater treatment is the process of removing contaminants from wastewater and household sewage, both runoff (effluents) and domestic. It includes physical, chemical, and biological processes to remove physical, chemical and biological contaminants. Sewage water can be polluted by a wide variety of substances, including pathogenic microorganisms, plant nutrients, toxic chemicals, sediments, heat oil, and radioactive substances (Sharpe 2003, Ishak et al. 2011). Sewage water is one of the major sources of human enteric pathogenic bacteria. Sewage contains human faeces and therefore contains human enteric pathogens i.e. Salmonella enterica, Salmonella enteritidis, Salmonella typhimurium, Shigella dysenteriae, Enterobacter spp., Vibrio spp. These pathogens are responsible for serious gastrointestinal illness which is a significant cause of waterborne health epidemics. Gastrointestinal disease is considered the third most common cause of death in the world (Hellier \& Williams 2007). For combating against these pathogens, antibiotics are generally used which has led to the evolution of multidrug-resistant strains of these pathogens. There is a great need to discover novel antibiotics due to the wide-spread emergence of resistance among pathogenic bacteria against available antibiotics (Goyal et al. 2010, Chauhan et al. 2015).

Although the discovery of antimicrobials leads to various expectations, it has been influenced by the emergence of resistant bacterial strains against antibiotics. It has been reported that the irrigation water system also has been contaminated by these multidrug-resistant bacteria which have a chance to enter in our food chain directly. The presence of multidrug-resistant enterobacter and enteric pathogens has been regarded as a serious problem for a community (Cabrera et al. 2004, Chitnis et al. 2004, Danchaivijitr et al. 2005). A significant increase of Multiple Antibiotic Resistant (MAR) bacteria is observed in various aquatic systems. Human infections caused by such bacteria could be difficult to treat with drugs (Chandrasekaran et al. 1998, Dicuonzo et al. 2001, Lopes et al. 2005).

The aim of this study was to evaluate the antibiotic resistance patterns of human enteric pathogenic bacteria which were isolated from different sewage waters from 
the suburb of Delhi. The study involves; (a) Collection of water samples from different sewage treatment plants (b) Isolation and identification of human enteric pathogens from sewage water samples (c) Determination of susceptibility and resistance pattern against ten different antibiotics by agar well diffusion assay (d) Interpretation of the data generated to determine the antibiotic resistance patterns of the isolated bacteria for the benefit of human welfare by increasing general awareness among the people.

\section{MATERIALS AND METHODS}

\section{(a) Collection of Water Samples}

1lt capacity of bottles was used to collect samples from 10 sewage treatment plants from different locations of Delhi (Table 1). Bottles used were sterilized using gamma radiations. Samples after collection were marked with SW01 to SW10. Sample collection and transportation to the laboratory were performed aseptically. Samples analysis was done within 6 hrs of collection.

\section{(b) Isolation and Identification of Human Enteric Pathogens}

Detection of Escherichia sp: Membrane filter of $0.45 \mu$ was passed with $250 \mathrm{~mL}$ water sample and placed in MacConkey broth. Eosin methylene blue agar and Mac Conkey agar were streaked for confirmatory identification. Characteristic pink colonies on the former and green metallic colonies on the latter are observed. Further confirmation was done by Gram's staining and HiMedia IMViC biochemical kit for E. coli as per IS: 5887(part-1)1976, Reaffirmed 2018.

Detection of Salmonella sp: Membrane filter of $0.45 \mu$ was passed with $250 \mathrm{~mL}$ water sample and placed in Buffer peptone water incubating at $37^{\circ} \mathrm{C}$ for 24 hours. $10 \mathrm{~mL}$ of Rappaport Vassiliadis medium is inoculated with $0.1 \mathrm{~mL}$ above grown sample and incubated at $42^{\circ} \mathrm{C}$ for 24 hours. Further streaking is done on Brilliant green agar and Bismuth sulphide agar where the former is observed for characteristic pink colonies and the latter for black metallic sheen colonies with $\mathrm{H}_{2} \mathrm{~S}$. Further confirmation was done by Gram's staining and HiMedia IMViC biochemical kit for Salmonella as per IS: 5887(Part-3) 1999, Reaffirmed 2018.

Detection of Pseudomonas sp: Membrane filter of $0.45 \mu$ was passed with $250 \mathrm{~mL}$ water sample and placed in Cetrimide broth and then incubated at $37^{\circ} \mathrm{C}$ for 48 hours. Cetrimide agar Plates were streaked and observed for characteristic green colonies and further confirmation was done by Gram's staining and Biochemical test as per IS: 13428:2005 (Annexure-D).

Detection of Vibrio sp: Membrane filter of $0.45 \mu$ was passed with $250 \mathrm{~mL}$ water sample and placed in alkaline peptone water and incubated at $37^{\circ} \mathrm{C}$ for 24 hours. TCBS Agar is streaked and further confirmed by HiMedia IMViC biochemical kit and Gram's staining as per IS: 5887(Part-5) 1976, Reaffirmed 2018.

Detection of Shigella sp: Membrane filter of $0.45 \mu$ was passed with $250 \mathrm{~mL}$ water sample and placed in Nutrient broth. Deoxycholate citrate agar is streaked for further confirmation and observed for characteristic colonies such as small opaque colonies. Further confirmation was done by HiMedia IMViC biochemical kit and Gram's staining for Shigella sp as per IS: 5887(part-7)1976, Reaffirmed 2018.

\section{(c) Molecular Identification}

Further identification of bacterial isolates using 16rrRNA sequencing is done. The sequence reaction using the Sanger dideoxy sequencing kit was performed following the manufacturer's instructions. Basic Local Alignment Search Tool (BLAST) algorithm is used for alignment of trimmed nucleotide sequences of different bacterial iso-

Table 1: Microbiological profiling of sewage water.

\begin{tabular}{|llll|}
\hline S.No. & Sampling Location & Sample Code & Pathogen identified with accession number \\
\hline 1. & Noida Industrial Effluents & SW01 & $\begin{array}{l}\text { Salmonella enterica, AE006468.2 } \\
\text { Escherichia albertii, NR_025569 }\end{array}$ \\
2. & Badarpur Power out & SW02 & Pseudomonas stutzeri, NR_113652.1 \\
3. & Badarpur Power in & SW03 & Salmonella typhimurium, AE006468.2 \\
4. & Okhla Head & SW04 & Shigella dysenteriae, NR_026332.1 \\
5. & DND Highway & SW05 & Pseudomonas aeruginosa, NR_117678.1 \\
6. & Nizamuddin & SW06 & Escherichia coli JCM1649, NR_112558.1 \\
7. & IP Powerhouse & SW07 & Escherichia marmotae HT073016, NR 136472.1 \\
8. & Rajghat Power House & SW08 & Pseudomonas fluorescence, NR_113647.1 \\
9. & Wazirabad Highway & SW09 & Vibrio cholerae, NR_119302.1 \\
10. & Nijafarbad Industrial Effluents & SW10 & Pseudomonas baetica, NR_116899.1 \\
\hline
\end{tabular}


lates provided by the National Centre for Biotechnology Information (NCBI).

\section{(d) Antibiotics and their Solutions}

Ten antibiotics like - STREPTOMYCIN (Streptomycin IP, Mfd by: Nicolas Piramal India LTD), TETRACYCLINE (Tetracycline hydrochloride capsules IP 250mg, Mfd by- Cipla limited), AMPICILLIN (Ampicillin hydrochloride capsules IP 250mg, Mfd by- Cipla limited), AMOXICILLIN (Amoxicillin Trihydrate capsules IP 250mg, Mfd byCipla limited), GENTAMYCIN (Gentamycin IP, Mfd by: Nicolas Piramal India LTD), DOXYCYCLINE (Doxycycline hydrochloride IP 100mg, Mfd by-Cipla limited), CLOXACILLIN (Cloxacillin sodium IP 500mg, Mfd by: Nicolas Piramal India LTD), METRONIDAZOLE (400mg, Mfd by- Eurolife Health Care), VANCOMYCIN (Vancomycin IP, Mfd by-Cipla limited) and MEROPENEM (Meropenem buffer sterile USP, Mfd by- Shenzhen Haibin pharmaceuticals) were used to check susceptibility and resistance pattern of above four bacterial isolates. All these antibiotics were obtained from a local pharmacy store and a working solution having $10 \mu \mathrm{g} / \mathrm{mL}$ concentration of each antibiotic was used for the study.

\section{(e) Inoculums Preparation}

$24 \mathrm{hr}$ old bacterial culture was taken for adjustment of $0.5 \mathrm{McF}$ arland density in densitometer to get a bacterial population of $1.0 \times 10^{8} \mathrm{cfu} / \mathrm{mL}$ using saline $(0.85 \%$ $\mathrm{NaCl})$

\section{(f) Agar Well Diffusion Assay (Zone of Inhibition Evaluation)}

The antibiotic assay was evaluated by agar well diffusion methods. Plates of sterile Muller Hinton Agar (MHA) with $100 \mu \mathrm{L}$ of each adjusted cultures was punched to $6 \mathrm{~mm}$ diameter well. $100 \mu \mathrm{L}$ of each antibiotic solution were added in wells (Chauhan et al. 2010, Kaushik \& Chauhan 2008). Plates were incubated at $37^{\circ} \mathrm{C}$ overnight. Zone of inhibition was observed in plates where the diameter of zones was calculated using Vernier callipers.

\section{RESULTS AND DISCUSSION}

In the present study, ten water samples were collected from ten different sewage water treatment plants located in Delhi. These samples were analysed for the presence of Escherichia sp, Salmonella sp, Pseudomonas sp, Shigella $s p$ and Vibrio sp.

During the study, three different strains of Escherichia i.e. Escherichia albertii, Escherichia coli JCM1649 and Escherichia marmotae four different strains of Pseudomonas, i.e. Pseudomonas stutzeri, Pseudomonas aeruginosa,

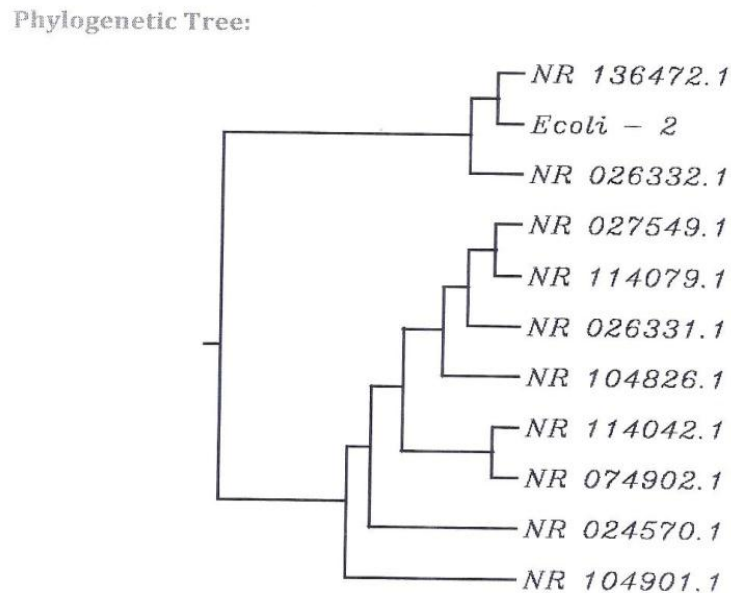

Primer Information

\begin{tabular}{|l|l|}
\hline PCR Primer name, Primer Sequences & Sequencing Primer name, Primer Sequences \\
\hline 27F 5' (AGAGTTTGATCMTGGCTCAS) 3' & 785F 5' (GGATTAGATACCCTGGTA) 3' \\
\hline 1492R 5' (TACGGYTACCTTGTTACGACTT) 3' & 907R 5' (CCGTCAATTCMTTTRAGTTT) 3' \\
\hline
\end{tabular}

Fig. 1: Molecular identification of Escherichia marmotae. 
Phylogenetic Tree:

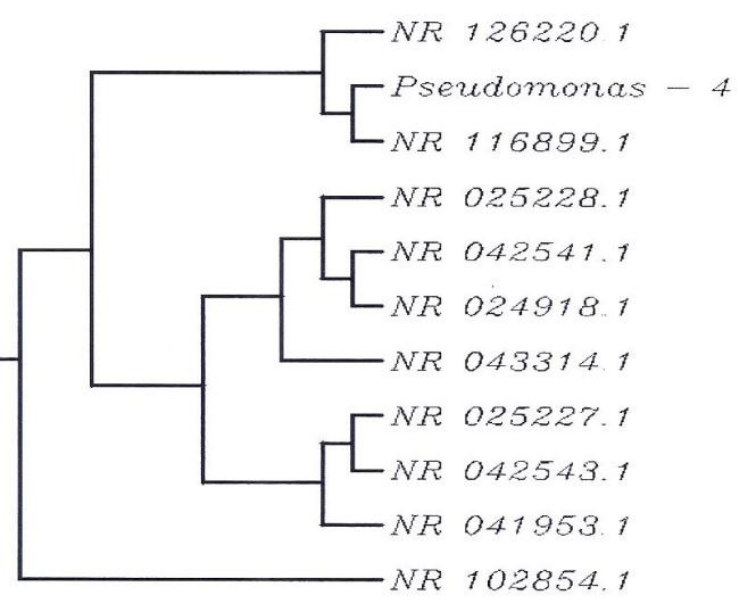

Primer Information

\begin{tabular}{|l|l|}
\hline PCR Primer name, Primer Sequences & Sequencing Primer name, Primer Sequences \\
\hline 27F 5' (AGAGTTTGATCMTGGCTCAS) 3' & 785F 5' (GGATTAGATACCCTGGTA) 3' \\
\hline 1492R 5' (TACGGYTACCTTGTTACGACTT) 3' & 907R 5' (CCGTCAATTCMTTTRAGTTT) 3' \\
\hline
\end{tabular}

Fig. 2: Molecular identification of Pseudomonas baetica.

Phylogenetic Tree:

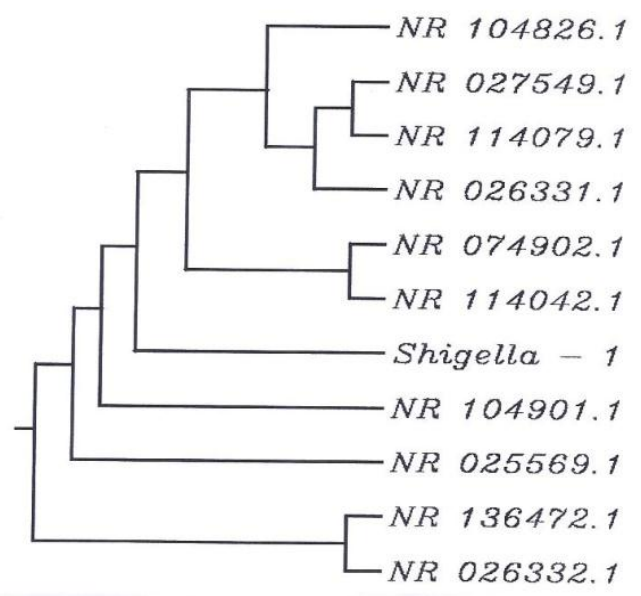

Primer Information

\begin{tabular}{|l|l|}
\hline PCR Primer name, Primer Sequences & Sequencing Primer name, Primer Sequences \\
\hline 27'= 5' (AGAGTTTGATCMTGGCTCAS) 3' & 785 5 5' (GGATTAGATACCCTGGTA) 3' $^{\prime}$ \\
\hline 1492R 5' (TACGGYTACCTTGTTACGACTT) 3' & 907 R 5' (CCGTCAATTCMTTTRAGTTT) 3' $^{\prime}$ \\
\hline
\end{tabular}

Fig. 3: Molecular identification of Shigella dysenteriae. 


\section{Phylogenetic Tree:}

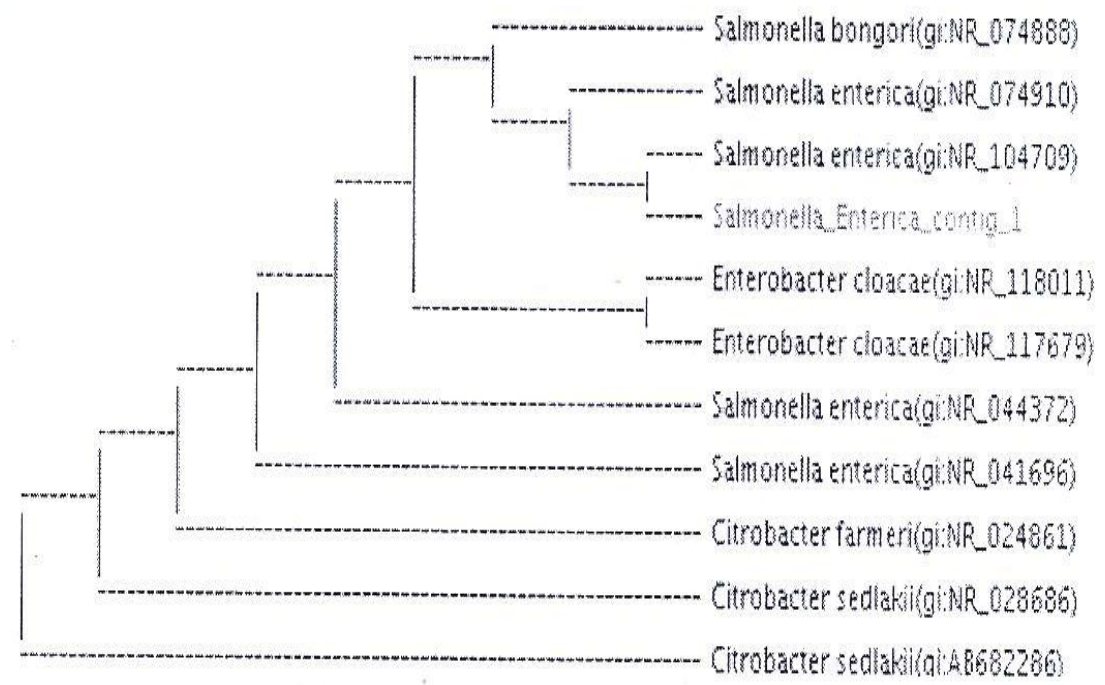

Primer Information

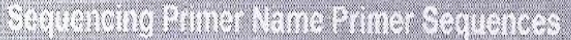

785F 5' (GGA TTA GAT ACC CTG GTA) 3'

907R 5' (CCG TCA ATT CMT TTR AGT TT) 3'

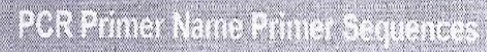

27F 5' (AGA GTT TGA TCM TGG CTC AG) 3

1492R 5' (TAC GGY TAC CTT GTT ACG ACT T) 3'

Fig. 4: Molecular identification of Salmonella enterica.

Phylogenetic Tree:

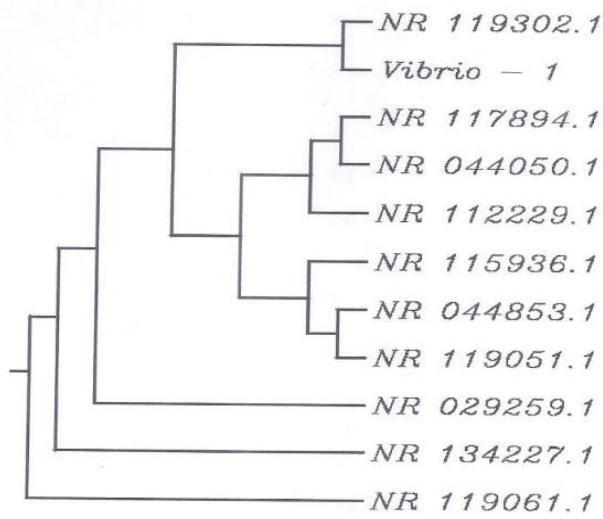

Primer Information

\begin{tabular}{|l|l|}
\hline PCR Primer name, Primer Sequences & Sequencing Primer name, Primer Sequences \\
\hline 27F 5' (AGAGTTTGATCMTGGCTCAS) 3' & $785 F 5^{\prime}$ (GGATTAGATACCCTGGTA) 3' \\
\hline 1492R 5' (TACGGYTACCTTGTTACGACTT) 3' & 907R 5' (CCGTCAATTCMTTTRAGTTT) 3' \\
\hline
\end{tabular}

Fig. 5: Molecular identification of Vibrio cholerae. 
Pseudomonas fluorescence and Pseudomonas baetica, two different strains of Salmonella, i.e. Salmonella enterica and Salmonella typhimurium, one Shigella dysenteriae and one Vibrio cholerae was identified Table 1. All the isolated strains were identified in this study exhibited 96 to $99 \%$ sequence similarity to the pathogenic enterobacteriaceae sequence available in NCBI database with lowest E-value and maximum query coverage and maximum identity. The multiple alignment file was then used to create phylogram (Fig. 1 to 5). Phylogenetic tree is a diagram that $r$ epresents evolutionary relationships among organisms. The pattern of branching in a phylogenetic tree shows how species or other groups evolved from a series of common ancestors.

Phylogenetic analysis explores the evolutionary relationships between organisms and is a key element for microbial studies. The development of phylogenetic trees is an important stage in characterizing new pathogens and develops new methods of treating various infections. Molecular sequencing technologies and phylogenetic approaches can be used to learn more about a new pathogen outbreak. This includes finding out about which species the pathogen is related to and subsequently the likely source of transmission. $16 \mathrm{~S}$ and $23 \mathrm{~S}$ rRNA gene sequence data reveal a closer relationship between Salmonella and Escherichia coli than between Salmonella and Citrobacter freundii (Christensen \& Olsen 1998). Escherichia fergusonii and Escherichia albertii are independent and established species (Seong et al. 2012, Farmer et al. 1985). However, these species were difficult to distinguish from $E$. coli by $16 \mathrm{~S}$ rRNA gene based phylogenetic analysis.

The susceptibility patterns of all isolated human enteric pathogenic strains were evaluated against ten commonly prescribed antibiotics by using an agar well diffusion assay. In this study, it is clearly seen that the bacterial isolates show non-vulnerability to different antibiotics. The antibiotic

Table 2: Antibiotic resistance patterns of different pathogens.

\begin{tabular}{|c|c|c|c|c|c|c|c|c|c|c|c|}
\hline \multirow{2}{*}{$\begin{array}{l}\text { Antibiotics } \\
\text { Used }\end{array}$} & \multicolumn{11}{|c|}{ Zone of inhibition* (in mm) } \\
\hline & $\begin{array}{l}\text { Escher- } \\
\text { ichia } \\
\text { albertii }\end{array}$ & $\begin{array}{l}\text { Escher- } \\
\text { ichia } \\
\text { marmotae }\end{array}$ & $\begin{array}{l}\text { Escheri- } \\
\text { chia coli } \\
\text { JCM1649 }\end{array}$ & $\begin{array}{l}\text { Pseu- } \\
\text { domonas } \\
\text { stutzeri }\end{array}$ & $\begin{array}{l}\text { Pseu- } \\
\text { domonas } \\
\text { aeruginosa }\end{array}$ & $\begin{array}{l}\text { Pseu- } \\
\text { domonas } \\
\text { fluores- } \\
\text { cence }\end{array}$ & $\begin{array}{l}\text { Pseu- } \\
\text { domonas } \\
\text { baetica }\end{array}$ & $\begin{array}{l}\text { Salmo- } \\
\text { nella } \\
\text { enter- } \\
\text { ica }\end{array}$ & $\begin{array}{l}\text { Salmo- } \\
\text { nella } \\
\text { typhimu- } \\
\text { rium }\end{array}$ & $\begin{array}{l}\text { Shigella } \\
\text { dysente- } \\
\text { riae }\end{array}$ & $\begin{array}{l}\text { Vibrio } \\
\text { chol- } \\
\text { erae }\end{array}$ \\
\hline Streptomycin & 21 & 23 & 17 & 17 & 19 & 18 & 21 & 22 & 21 & 14 & 11 \\
\hline Gentamycin & 13 & 15 & 14 & 15 & 17 & 15 & 16 & 0 & 20 & 0 & 13 \\
\hline Tetracycline & 20 & 18 & 19 & 0 & 0 & 11 & 23 & 17 & 0 & 16 & 0 \\
\hline Amoxicillin & 0 & 0 & 24 & 11 & 19 & 14 & 0 & 20 & 21 & 18 & 17 \\
\hline Ampicillin & 0 & 0 & 24 & 12 & 14 & 13 & 15 & 19 & 21 & 20 & 16 \\
\hline Doxycycline & 0 & 0 & 0 & 0 & 0 & 0 & 0 & 0 & 0 & 0 & 0 \\
\hline Meropenem & 22 & 26 & 27 & 25 & 22 & 26 & 29 & 21 & 24 & 28 & 29 \\
\hline Vancomycin & 0 & 0 & 18 & 0 & 15 & 17 & 26 & 17 & 19 & 0 & 12 \\
\hline Metronidazole & 0 & 0 & 0 & 0 & 0 & 0 & 0 & 0 & 0 & 0 & 0 \\
\hline Cloxacillin & 0 & 26 & 19 & 14 & 12 & 15 & 22 & 20 & 18 & 14 & 0 \\
\hline
\end{tabular}

*Zone of inhibition in $\mathrm{mm}$. Diameter including well diameter of $6.0 \mathrm{~mm}$

Table 3: Percentage of pathogens susceptible to antibiotics.

\begin{tabular}{|c|c|c|c|c|c|}
\hline \multirow[t]{2}{*}{ Antibiotic used } & \multicolumn{5}{|c|}{$\%$ Susceptible pathogens } \\
\hline & Escherichia $\mathrm{sp}$ & Pseudomonas sp & Salmonella $\mathrm{sp}$ & Shigella sp & Vibrio $\mathrm{sp}$ \\
\hline Streptomycin & 100 & 100 & 100 & 100 & 100 \\
\hline Tetracycline & 100 & 50 & 50 & 100 & NZI \\
\hline Amoxicillin & 33 & 75 & 100 & 100 & 100 \\
\hline Ampicillin & 33 & 100 & 100 & 100 & 100 \\
\hline Meropenem & 100 & 100 & 100 & 100 & 100 \\
\hline Vancomycin & 33 & 75 & 100 & NZI & 100 \\
\hline Metronidazole & NZI & NZI & NZI & NZI & NZI \\
\hline Cloxacillin & 66 & 100 & 100 & 100 & NZI \\
\hline
\end{tabular}

NZI: No Zone of Inhibition 
resistance patterns in terms of average zones of diameter considering 4 plates for bacterial isolates against each of ten antibiotics of $10 \mu \mathrm{g} / \mathrm{mL}$ concentration were calculated and shown in Table 2. The most vulnerable antibiotic was found to be Doxycycline and Metronidazole against which all eleven isolated human enteric pathogens shows $100 \%$ resistance (Fig. 6). The percentage of susceptibility against antibiotics was demonstrated in Table 3. All three Escherichia isolates were shown $100 \%$ susceptible against Streptomycin, Gentamycin, Tetracycline and Meropenem. Intermediate susceptibility was shown by Escherichia i.e. $66 \%$ towards Cloxacillin. In the case of four Pseudomonas isolates 100\% susceptible against Streptomycin, Gentamycin, Ampicillin and Meropenem. Intermediate susceptibility ranges from 50\% to $75 \%$ towards the rest of antibiotics except Doxycycline and Metronidazole. However, two Salmonella isolates have shown more susceptibility against six antibiotics used in this study. Both Salmonella enteric and Salmonella typhimurium have shown $50 \%$ susceptibility against Gentamycin and Tetracycline. In the case of Shigella dysenteriae and Vibrio cholera both have shown $100 \%$ resistance against four antibiotics. Susceptibility in terms of zone of inhibition against antibiotics used in the study was shown in Fig. 7a to 7e. Multiple antibiotic resistances have shown by eleven human enteric pathogens isolated. Meropenem was found to be the most promising antibiotic as all eleven human enteric pathogens have shown a high level of susceptibility followed by Streptomycin, Ampicillin, Cloxaxillin, Gentamycin, Amoxicillin, Tetracycline, Vancomycin and Metronidazole. The cumulative effectiveness of the antibiotics as obtained in this study is Meropenem $>$ Streptomycin $>$ Ampicillin $>$ Cloxaxillin $>$ Gentamycin $>$ Amoxicillin $>$ Tetracycline $>$ Vancomycin $>$ Metronidazole.

Antibiotics are an essential part of combating harmful bacterial infections in vivo. During the last few decades, infectious diseases have played a significant role in the death of millions in developing countries like India. Because of the mutagenic nature of bacterial DNA, the rapid multiplication of bacterial cells, and the constant transformation of bacterial cells due to plasmid exchange and uptake, pathogenic bacteria continue to develop antimicrobial resistance, thus rendering certain antibiotics useless (Kaushik et al. 2008). It is thus become important to determine the antibiotic resistance pattern of isolated microbes as it is the part of microbial monitoring process of the water (Chatterjee et al. 2012).

The presence of multidrug resistance in human enteric pathogens is not uncommon recently, and its severity has been expanded from town to village and village to everywhere very rapidly. The rapid development of the antibiotic

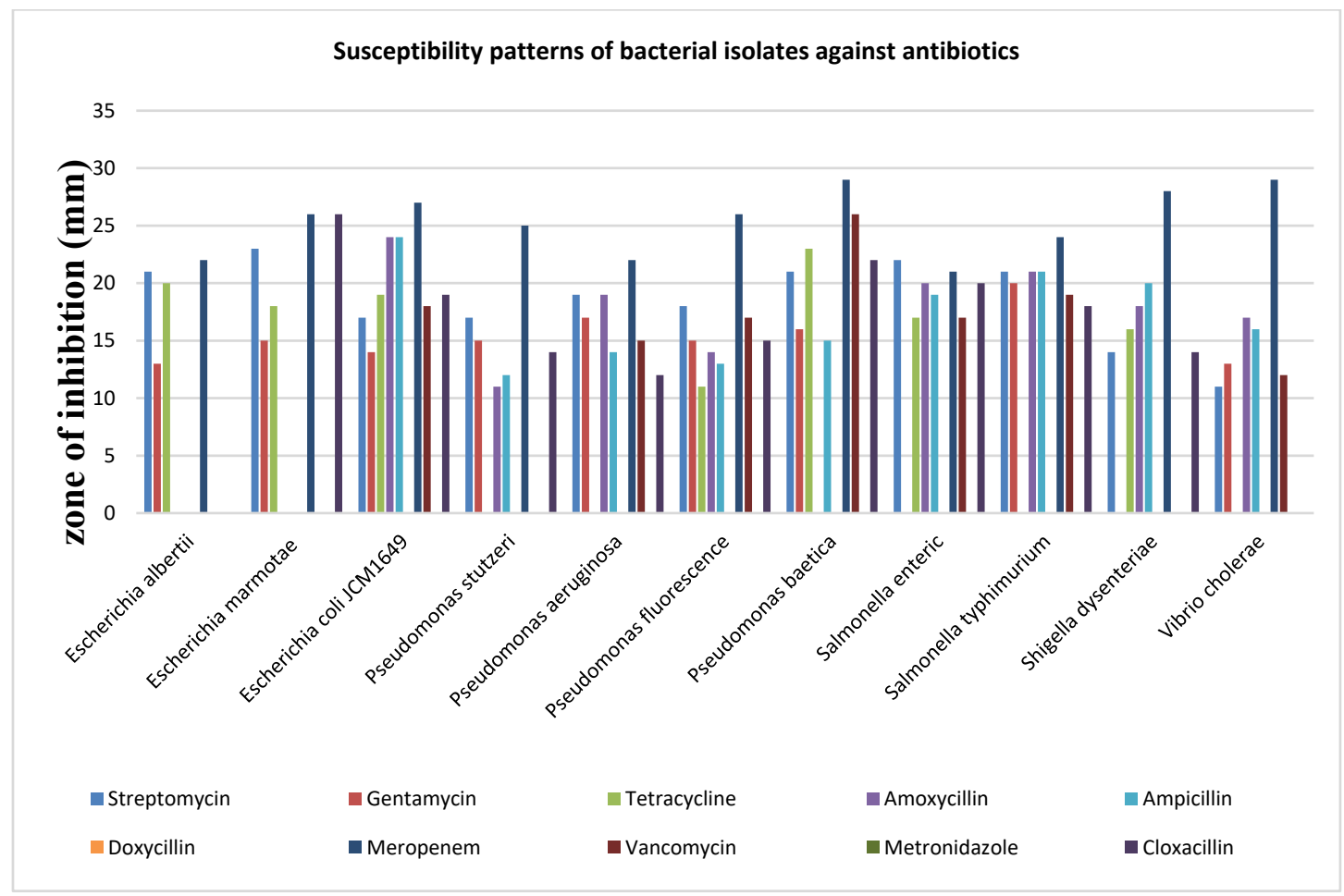

Fig. 6: Susceptibility patterns of bacterial isolates against antibiotics. 


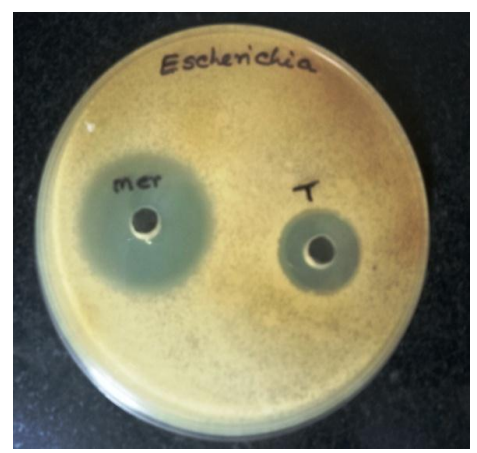

(a)

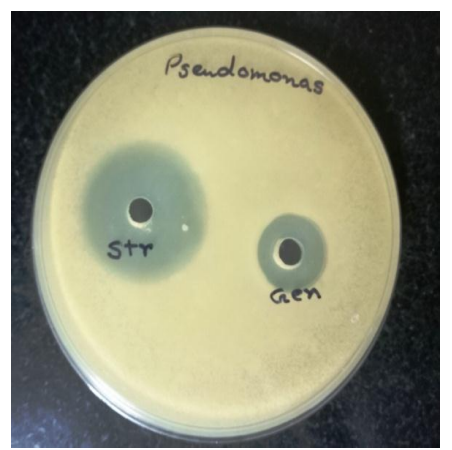

(b)

a) Escherichia marmotae against Meropenem and Tetracycline

b) Pseudomonas baetica against Streptomycin and Gentamycin

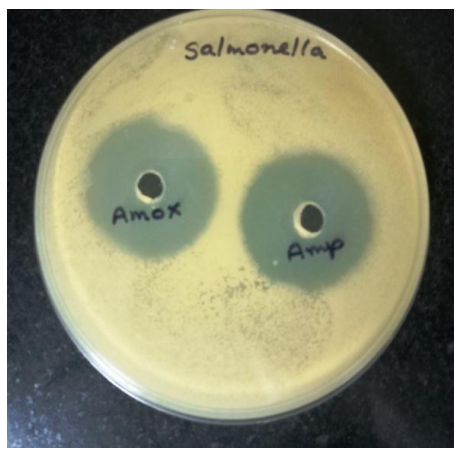

(c)

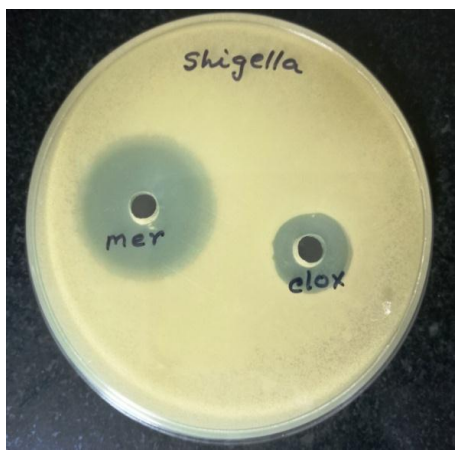

(d)

c) Salmonella enteric against Amoxicillin and Ampicillin

d) Shigella dysenteriae against Meropenem and Cloxacillin

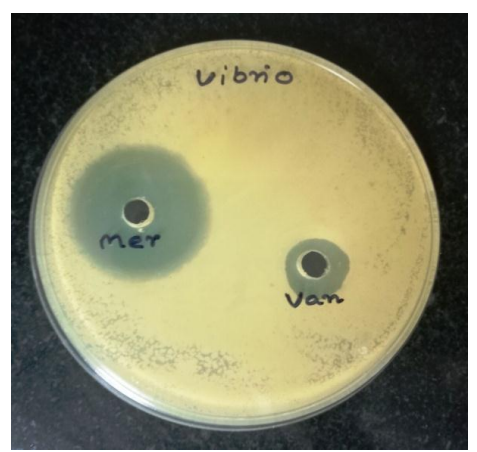

(e)

e) Vibrio cholerae against Meropenem and Vancomycin

Mer: Meropenem, Van: Vancomycin, T: Tetracycline, Str: Streptomycin,

Gen: Gentamycin, Amox: Amoxicillin, Amp: Ampicillin, Clox: Cloxacillin

Fig. 7: Zone of inhibition of bacterial isolates against antibiotics. 
resistant pattern of $E$. coli, as well as other microorganisms, might create a devastating health problem (Chauhan \& Goyal 2013, Overdevest et al. 2011). Based open these study it was found that most of the isolates in the present study showed multiple tolerances to antibiotics. Since heavy metals are all similar in their toxic mechanism, multiple tolerances are common phenomena among heavy metal resistant bacteria (Chauhan et al. 2015). In sewage water, some substances have the potential to select for antibiotic resistance even though they are not antibiotics themselves. Heavy metals and biocides are two of them. Exposure to heavy metals or biocides results in the selection of bacterial strain also able to resist antibiotics. This shows that there is a close association between metal resistance and antibiotic resistance.

\section{CONCLUSION}

An alarming consequence has been occurred due to the widespread emergence of resistance among microorganisms against clinically significant antibiotics. It is clearly indicated that domestic waste and industrial waste are responsible for the development of bacterial resistance along with the risk of human health and the environment. Regular surveillance of the effluent in industrial sites is a must if the risk of disease due to such antibioticresistant organisms is to be avoided. Antibiotic resistance development among bacteria is a challenging issue that requires the improvement of next-generation treatment processes in sewage water treatment plants. The emergence of antibiotic resistance among pathogens increases the demand for novel treatment strategies. In this study, results were indicative of very high antimicrobial resistance to Doxycycline and Metronidazole among all bacterial isolates involved in our study. The uncontrolled use of this antibiotic led to the generation of multi-drug resistant strains. The fourth-generation antibiotic i.e. Meropenem is found to have significant efficacy and can be considered appropriate for the empirical treatment of the above four bacterial infections. Alternatives to antibiotics such as herbal medicines, probiotics and lytic bacteriophages can help to decrease the burden of antimicrobial resistance globally. Although the present study can lead to beneficially assist in the identification of alternate drug to control these multidrug-resistant bacterial strains.

\section{ACKNOWLEDGMENTS}

The authors are thankful to Dr. K.M. Chacko, Director, Shriram Institute for Industrial Research, Delhi; for facilitating and encouraging the research work.

\section{REFERENCES}

Cabrera, R., Ruiz, J., Marco, F., Oliveira, I. and Arroyo, M. 2004. Mechanism of resistance to several antimicrobial agents in Salmonella clinical isolates causing traveller's diarrhoea. Antimicrobial Agents Chemotherapy, 48(10): 3934-3939.

Chandrasekaran, S., Venkatesh, B. and Lalithakumari, D. 1998. Transfers and expressions of a multiple antibiotic resistance plasmid in marine bacteria. Current. Microbiol., 37: 347-351.

Chatterjee, R., Sinha, S., Aggarwal, S., Dimri, A., Singh, D., Goyal, P., Chauhan, A., Aggarwal, M.L. and Chacko, K.M. 2012. Studies on susceptibility and resistance patterns of various $E$. coli isolated from different water samples against clinically significant antibiotics. International journal of Bioassay, 01(11): 156-161.

Chauhan, A. and Goyal, P. 2013. Isolation and Identification of Escherichia coli from various foodstuffs and their resistance against clinically significant antibiotics. J. Advance in Biology, 2: 45-53.

Chauhan, A., Garg, S. and Ranjan, A. 2018. Prevalence of microbial contamination of mobile cell phones in general population of Delhi, India. J. Exp. Clin. Microbiol., 1(1): 12-15.

Chauhan, A., Garima, G., Goyal, P. and Kaushik, P. 2010. In vitro antibacterial evaluation of Anabaena sp. against several clinically significant microflora and HPTLC analysis of its active crude extracts. Indian Journal of Pharmacology, 42(2): 105-107.

Chauhan, A., Goyal, P., Verma, A. and Jindal, T. 2015. In -vitro antibiotic resistance and heavy metal tolerance patterns of gram-positive and gram-negative bacteria isolated from effluent treated water of Delhi, India. Journal of Current Pharma Research, 5(2): 1449-1458.

Chauhan, A., Goyal, P., Verma, A. and Jindal, T. 2015. Microbiological evaluation of drinking water sold by roadside vendors of Delhi, India. Appl. Water Sci., DOI 10.1007/s13201-015-0315-x.

Chitnis, V., Chitnis, S., Vaidya, K., Ravikant, S. and Patil, S. 2004. Bacterial population changes in hospital effluent treatment plant in central India. Water Research, 38(2): 441-447.

Christensen, H. and Olsen, J. E. 1998. Phylogenetic relationships of Salmonella based on DNA sequence comparison of atpD encoding the beta subunit of ATP synthase. FEMS Microbiol. Lett., 161: 89-96.

Danchaivijitr, S., Wongchanapai, W., Assanasen, S. and Jintanothaitavorn, D. 2005. Microbial and heavy metal contamination of treated hospital wastewater in Thailand. J. Med. Assoc. Thai., 88(10): S59-S64.

Dicuonzo, G., Gherardi, G., Lorino, G., Angeletti, S., Battistoni, F. and Bertuccini, L. 2001. Antibiotic resistance and genotypic characterization by PFGE of Clinical and environmental isolates of Enterococci. FEMS Microbial Letters, 201:205-211.

Farmer III J.J., Fanning G.R., Davis, B.R., O'Hara, C.M., Riddle, C., Hickman-Brenner, F.W., Asbury, M.A., Lowery III, V.A. and Brenner, D.J. 1985. Escherichia fergusonii and Enterobacter taylorae, two new species of Enterobacteriaceae isolated from clinical specimens. J. Clin. Microbiol., 21: 77-81.

Goyal, P., Chauhan, A. and Kaushik, P. 2010. Assessment of Commiphora wightii (Arn.) Bhandari (Guggul) as potential source for antibacterial agent. Journal of Medicine and Medical Sciences, 1(3): 071-075.

Hellier, M.D. and Williams, J.G. 2007. The burden of gastrointestinal disease: Implications for the provision of care in the UK. Gut,. 56: 165-166.

IS 13428: 2005. Detection and Enumeration of Pseudomonas aeruginosa (Annexure-D).

IS 5887 (Pt-1) 1976. Reaff: 2018. Isolation, Identification and Enumeration of Escherichia coli.

IS 5887 (Pt-3) 1999. Reaff: 2018. General Guidance on methods for the detection of Salmonella.

IS 5887 (Pt-5) 1976, Reaff: 2018 Isolation, Identification and Enumeration of Vibrio cholerae and Vibrio parahaemolyticus. 
IS 5887 (Pt-7) 1976, Reaff: 2018. Isolation, Identification and Enumeration of Shigella.

Ishak, W.M.F.W., Jamek, S., Jalanni, N.A. and Jamaludin, N.F.M. 2011. Isolation and identification of bacteria from activated sludge and compost for municipal solid waste treatment system. International Conference on Biology, Environment and Chemistry. 24: 450-454.

Kaushik, P. and Chauhan, A. 2008. In vitro antibacterial activity of laboratory grown culture of Spirulina platensis. Indian Journal of Microbiology, 48(3): 348-352.

Kaushik, P. and Goyal, P. 2008. In vitro evaluation of Datura innoxia (thorn-apple) for potential antibacterial activity. Indian Journal of Microbiology, 48(3): 353-357.

Lopes, M. F. S., Riberio, T., Abrantes, M., Marques, J.J. F., Tenreirom, R. and Crespo, M.T.B. 2005. Antimicrobial resistance profiles of dairy and clinical isolate and type strains of entercocci. Int. J. Food Microbial., 103: 191-198.

Overdevest, I., Willemsen, I., Rijnsburger, M., Eustace, A. and Xu, L. 2011. Extended-spectrum $\beta$-lactamase genes of Escherichia coli in chicken meat and humans. The Netherlands. Emerg. Infect. Dis., 17(7): 1216-1222.

Seong, W.J., Kwon, H.J., Kim, T.E., Lee, D.Y., Park, M.S. and Kim, J.H. 2012. Molecular serotyping of Salmonella enteric by complete rpoB gene sequencing. J. Microbiol., 50: 962-9.

Sharpe, M. 2003. High on pollution: drugs as environmental contaminants. Journal of Environmental Monitoring, 5(3): 43-46.

Wise, R., Hart, T., Cars, O., Streulens, M. and Helmuth, R. 1998. Antimicrobial resistance is a major threat to public health. BMJ, 317(7159): 609-610. 